\title{
Aquisição de imagens ultrassônicas como experimento didático
}

\author{
Ultrasound image acquisition as a didactic tool
}

\author{
Manuel Blanco Valentín*1, Clécio R. de Bom ${ }^{1,2}$, Márcio P. de Albuquerque ${ }^{1}$, Marcelo P. de \\ Albuquerque $^{1}$, Elisângela L. Faria ${ }^{1}$, Maury D. Correia ${ }^{3}$ \\ ${ }^{1}$ Coordenação de Atividades Técnicas (CAT/CBPF), Centro Brasileiro de Pesquisas Físicas, Rua Dr. Xavier Sigaud, 150 - Ed. \\ César Lattes, Urca, Rio de Janeiro, RJ, CEP: 22290-180, Brasil. \\ ${ }^{2}$ Centro Federal de Educação Tecnológica Celso Suckow da Fonseca, Rodovia Mário Covas, lote J2, quadra J, Distrito \\ Industrial de Itaguaí, Itaguaí, RJ, CEP: 23810-000, Brasil. \\ ${ }^{3}$ Centro de Pesquisas e Desenvolvimento Leopoldo Américo Miguez de Mello - CENPES, PETROBRÁS, Av. Horácio Macedo, \\ 950, Cidade Universitária, Rio de Janeiro, RJ, CEP: 21941-915, Brasil.
}

Recebido em 15 de Julho, 2017. Revisado em 18 de Setembro, 2017. Aceito em 22 de Setembro, 2017.

\begin{abstract}
O estudo das ondas sonoras com suas diversas aplicações é um tema presente na formação do estudante de ensino médio e superior que pode ser utilizado para demonstrar conceitos de física ondulatória de forma bastante didática. Neste trabalho discutimos um experimento visando uma aplicação tecnológica presente em diversas áreas como medicina e engenharia: a geração de Imagens de Ultrassom. Introduzimos o princípio físico que permite a medida de distância mediante transdutores ultrassônicos. Exploramos o método utilizado para captar, filtrar e processar essas medidas. Através do processamento digital das mesmas é possível exibir imagens que, de forma gráfica, permitem visualizar obstáculos na área visual do transdutor. O experimento pode ser utilizado de forma ilustrativa ou para uma análise quantitativa. Devido à baixa complexidade da montagem é possível que o docente oriente a construção do mesmo a fim de desenvolver habilidades em um contexto interdisciplinar.
\end{abstract}

Palavras-chave: Processamento digital, Imagem Ultrassônica, transdutor HC-SR04.

\begin{abstract}
The study of sound waves is a common subject for high school or college students which has different applications. It is also fairly instructional and useful for illustrating basic wave theory concepts. In this work we discuss an experiment regarding a technological application that is present in many different areas such as medicine and engineering: the generation of ultrasound images. We introduce the physical principle that allows the measurement of distance using ultrasound transducers, as well as the methodology used to capture, filter and process these measurements. Through the digital processing of these images we can display them in a way that allows us to identify obstacles placed in the visual area of the sensor. This experiment can be used for educational purposes or for a quantitative analysis. Due to the easy processes involved in the building and processing steps, teachers might find its construction useful for the development of interdisciplinary skills.
\end{abstract}

Keywords: Digital Processing, Ultrasound image, HC-SR04 transducer.

\section{Introdução}

O ensino de física tradicional, que se restringe unicamente à apresentação da teoria e conceitos, vem perdendo grande espaço em sala de aula. Considerando o acesso dos estudantes à informação e tecnologia, a percepção é de que a simples exposição dos assuntos no quadro é desestimulante e abstrata. Esse fenômeno tem um impacto relevante no processo de ensino-aprendizagem, onde se espera que o estudante atribua sentido ao que está aprendendo. Os Parâmetros Curriculares Nacionais do Ensino Médio [1,2] orientam os docentes da área de ciências sobre como estimular a compreensão da natureza e suas tecnologias com o objetivo do exercício crítico da plena

*Endereço de correspondência: mbvalentin@cbpf.br cidadania do estudante. Sob esta perspectiva, o uso de tecnologia, experimentos e demonstrações didáticas têm um grande apelo junto aos estudantes com potencial para contribuir na formação dos mesmos, enriquecendo a experiência de sala de aula. Diversos trabalhos têm explorado essa abordagem, sob diferentes óticas como, por exemplo, 3 . 4 .

Neste trabalho abordamos o estudo das ondas sonoras, em particular a questão da geração de imagens de ultrassom. O uso de ultrassom como detector de distância ou para geração de imagens possui diversas aplicações tecnológicas [5]. Atualmente, o sonar é amplamente utilizado, seja em navios militares, submarinos, navios comerciais ou embarcações científicas, as quais conseguem monitorar, por exemplo, a quantidade e movimento de 
uma certa biomassa de um ecossistema [6]. Este tipo de equipamento também pode realizar um mapeamento de uma certa superfície mediante a emissão e recepção de ondas de ultrassom, criando assim imagens de distância, e possibilitando a detecção de qualquer tipo de objeto ou obstáculo na superfície varrida. Uma das aplicações mais conhecidas do sonar, porém, é a de detecção de objetos no leito marinho, mediante a qual é possível achar, por exemplo, navios naufragados [7].

O intervalo de frequências sonoras utilizadas nestes equipamentos podem variar desde infrassons, que permitem medir maiores distâncias, até ultrassons, que proporcionam maior resolução. Os ultrassons, isto é, sons com frequência superiores a $20 \mathrm{kHz}$, são inaudíveis para seres humanos ${ }^{1}$, e possuem diversas aplicações em medicina como, por exemplo, na visualização de fetos [9] ou na detecção de tecidos tumorais [10].

Uma aplicação de interesse destes transdutores ultrassônicos é a de caracterização de poços e reservatórios de hidrocarbonetos 11,12]. Essa análise é uma técnica complementar na determinação e construção de modelos dos possíveis recursos energéticos. Essa abordagem consiste em introduzir uma sonda que contém um transdutor ultrassônico, que mediante a rotação e conforme a mesma penetra no poço, permite obter imagens acústicas do mesmo. A sonda obtém os valores de tempo de trânsito das ondas ultrassônicas emitidas no poço (o que permite saber a geometria do mesmo) e de absorção acústica (o que permite inferir texturas de rochas presentes nas paredes do poço). As sondas Schlumberger 13], por exemplo, são capazes de realizar estas medidas. Um exemplo de imagem ultrassônica de um poço deste tipo, denominada UBI, do inglês Ultrassonic Borehole Image, é mostrada na Fig. 1 .

$\mathrm{Na}$ montagem discutida neste trabalho, propomos a utilização do transdutor HC-SR04 [14] com auxílio de uma placa de Arduino para medir distâncias e gerar imagens processadas com ajuda do MATLAB. Em particular este transdutor já foi explorado em [15,16] com dois objetivos distintos: análise de vibrações mecânicas e estudo do oscilador harmônico. Utilizando o enfoque da geração de imagens, discutimos os princípios físicos envolvidos, destacando os limites de aplicabilidade e sugerimos as possíveis aplicações no ensino de Física.

Este trabalho está dividido da seguinte forma: na seção 2 discutimos os princípios físicos envolvidos, na seção 3 descrevemos o transdutor utilizado, a montagem experimental e os detalhes de como a medida de distância é realizada. A seguir, na seção 4 apresentamos o fluxograma de processamento dos dados obtidos, descrevendo cada etapa. Na seção 5 discutimos algumas medidas experimentais e as possíveis fontes de erro. Na seção 6 fazemos algumas considerações sobre as aplicações no ensino da Física e na seção 7 apresentamos nossas conclusões. Por último, também incluímos no apêndice uma lista dos

\footnotetext{
${ }^{1}$ Cabe mencionar, porém, que estas ondas afetam negativamente alguns animais, como por exemplo alguns tipos de cetáceos 8.
}

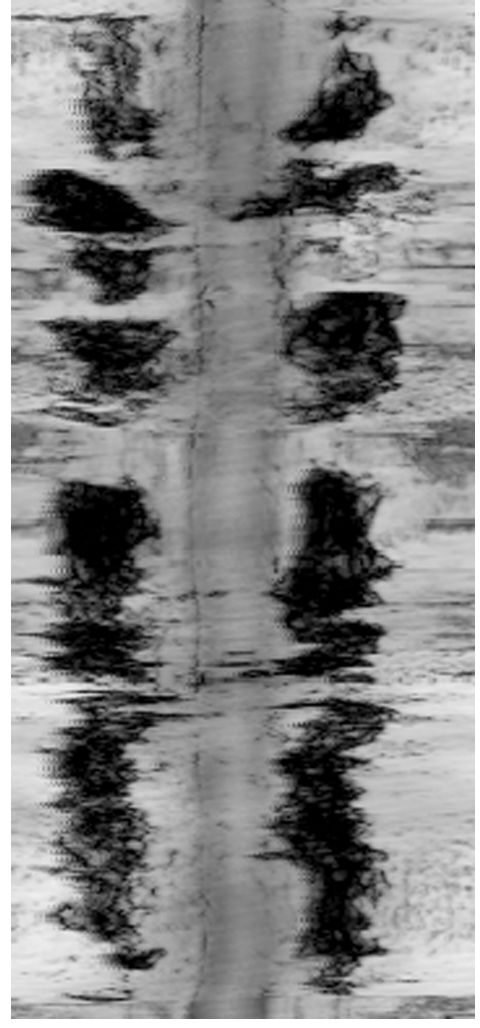

Figura 1: Imagem UBI de um poço no solo marinho de impedância acústica a partir da medida de absorção acústica da rocha [13].

materiais necessários para a construção do protótipo proposto.

\section{Princípio físico da medida com sensores ultrassônicos}

Para transdutores de ultrassom existem duas medidas de interesse relacionadas ao fenômeno da onda refletida:

1. Absorção acústica do material: Depende das características físicas do material como porosidade, densidade, índices de reflexão acústica, etc.

2. Tempo de trânsito: Efeito que permite determinar a distância do objeto ao transdutor e base deste projeto.

Ondas acústicas são ondas de pressão (no caso do presente trabalho, se propagando no ar) e podem ser descritas pela equação de onda apresentada em (1),

$$
\nabla^{2} p-\frac{1}{v_{c}^{2}} \frac{\partial^{2} p}{\partial t^{2}}=0
$$

onde $p$ é a pressão e $v_{c}$ velocidade de propagação da onda, que depende do meio físico no qual a mesma está se propagando [17, 18]. Uma vez emitida pela fonte, a onda se propagará segundo a equação (1) até encontrar um 
obstáculo. No momento em que a onda se encontre com um obstáculo, diversos fenômenos poderão ocorrer, entre os quais destacamos: absorção, refração, reverberação e reflexão 18,19]. O foco deste trabalho será na reflexão. Este fenômeno pode ser caracterizado pelo coeficiente de reflexão acústica que depende do meio material.

A reflexão acústica nos permite calcular a distância entre o obstáculo que refletiu a onda e o foco, da seguinte forma: o foco emite uma onda acústica durante um certo período conhecido e um receptor, posicionado o mais próximo possível do foco, recebe o sinal da onda refletida. O intervalo de tempo entre a emissão e a recepção é chamado de tempo de trânsito. A partir da velocidade da onda acústica no meio, $v_{c}$, e do tempo de trânsito, $\Delta t$, é possível inferir o valor da distância $d$ entre a fonte e o obstáculo:

$$
d=v_{c} \frac{\Delta t}{2} .
$$

Neste contexto as medidas foram realizadas a uma temperatura ambiente de aproximadamente $20^{\circ} \mathrm{C}$ e uma pressão atmosférica aproximada de $1 \mathrm{~atm}$, portanto a velocidade de propagação do som no ar considerada foi $344 \mathrm{~m} / \mathrm{s}$ [20.

É possível ilustrar o processo de obtenção de imagens ultrassônicas a partir da medida da distância como apresentado na Fig. 2. Consideremos, inicialmente, uma superfície plana a uma altura constante sobre a qual se encontra um paralelepípedo de altura $h$, cuja vista em planta seria equivalente à mostrada na Fig. 22 Agora suponhamos que dividimos a superfície (planta) em porções quadradas do mesmo tamanhd ${ }^{2}$ Desta forma, obteríamos uma matriz de valores de altura ordenados, que seria uma representação aproximada da planta (Discretização da altura na Fig. 2). A partir da matriz de valores de altura, então, é possível obter imagens da superfície medida, após o processamento digital.

\section{Método de medida de distância com o transdutor HC-SR04}

Existem diversos transdutores ultrassônicos no mercado que permitem emitir e receber ondas acústicas. Dentre todas as opções foi escolhido o transdutor HC-SR04 fabricado pela empresa Cytron Technologies devido à sua relação custo/benefício.

O HC-SR04, mostrado na Fig. 3, é um transdutor que incorpora emissor e receptor na mesma estrutura. $\mathrm{O}$ funcionamento do transdutor é simples e muito utilizado em aplicações de detecção de obstáculos com ultrassons 22,23 .

\footnotetext{
${ }^{2} \mathrm{O}$ tamanho destes quadrados está relacionado à resolução da imagem final obtida, segundo a teoria da amostragem de NyquistShannon 21]. Segundo a mesma, o tamanho mínimo deste quadrado (pixel da imagem final) deveria ter, no mínimo, a metade do comprimento mínimo que se deseja medir.
}

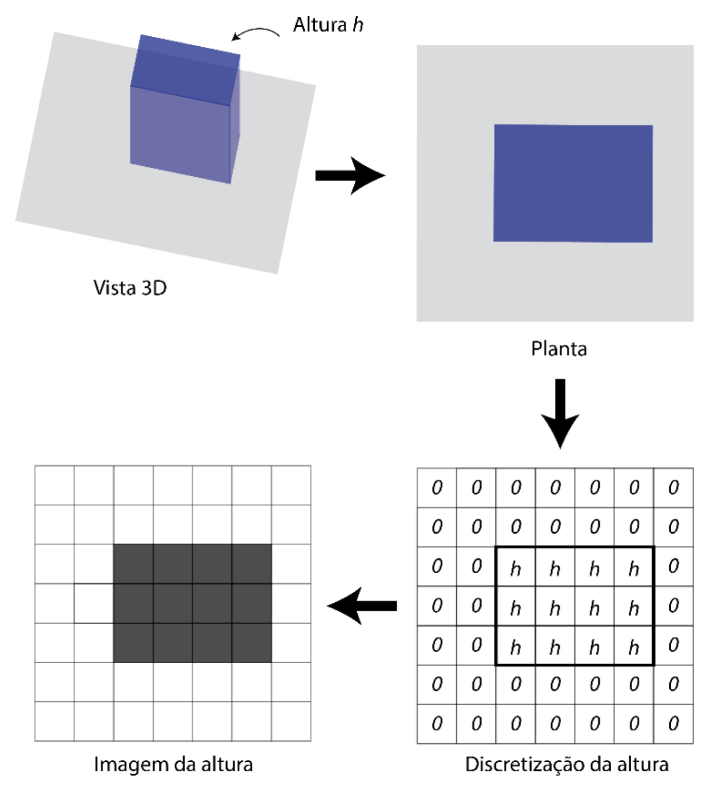

Figura 2: llustração do processo de geração de imagens a partir da medição de altura.

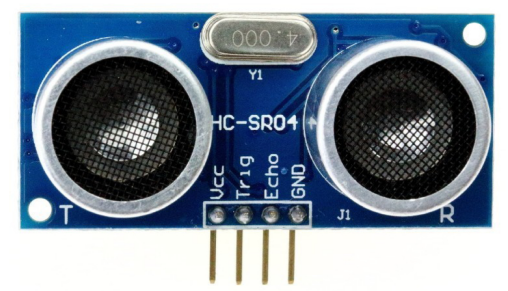

Figura 3: Imagem do transdutor ultrassônico HC-SR04 utilizado neste projeto. Reproduzido de [14].

\subsection{Características do sensor}

As características elétricas (mínimas, típicas e máximas) do transdutor são apresentadas na Tabela 1 A tecnologia utilizada no sensor é do tipo TTL (Transistor-Transistor Logic, informações adicionais disponíveis em [24]), o que oferece uma grande compatibilidade com todo tipo de sistemas.

Para a realização das medidas, é necessário considerar as características do transdutor relacionadas à própria medida de distância. Estas características são mostradas na Tabela 2 . Como se pode observar na mesma, o transdutor oferece um intervalo de medida que varia de um mínimo de $3 \mathrm{~cm}$ até um máximo de $4 \mathrm{~m}$. Este intervalo, assim como a resolução do mesmo, é suficiente para os objetos imageados neste trabalho.

Tabela 1: Características elétricas do transdutor HC-SR04 14].

\begin{tabular}{lccc}
\hline & Mín. & Típ. & Máx. \\
\hline Voltagem de Alimentação (V) & 4,5 & 5,0 & 5,5 \\
Consumo em Operação (mA) & 10 & 15 & 20 \\
Consumo em Repouso (mA) & 1,5 & 2,0 & 2,5 \\
\hline
\end{tabular}


Tabela 2: Parâmetros de operação do transdutor HC-SR04 14.

\begin{tabular}{lcc}
\hline & Mín. & Máx. \\
\hline Frequência de Operação $(\mathrm{kHz})$ & 40 & - \\
Intervalo distância mensurável $(\mathrm{cm})$ & 3 & 400 \\
Resolução $(\mathrm{cm})$ & - & 0,3 \\
\hline
\end{tabular}

\subsection{Esquema de montagem do suporte mecânico}

Com base no exemplo dado para a Fig. 2, para realizar a medida da distância de forma efetiva é necessário discretizar a superfície em estudo. Para tal, foi criado um suporte mecânico quadrado sobre o qual o transdutor e o sistema de aquisição de dados (Arduino UNO) foram montados.

Uma ilustração do esquema do suporte mecânico pode ser vista na Fig. 4 A estrutura possui quatro pivôs deslizantes sobre quatro aberturas feitas no suporte mecânico, nas quais quatro elementos deslizantes foram incorporados. Estes pivôs estão conectados em pares, cada um com o par da sua frente, através de varas de metal. As varas são introduzidas em um elemento de acrílico sob o qual foi montado o sensor. Desta forma é possível movimentar o sensor por toda a estrutura de forma independente em cada um dos dois eixos do movimento (horizontal e vertical), permitindo assim varrer cada linha e cada coluna da superfície a ser analisada. Finalmente, o objeto a ser medido é colocado sob o suporte mecânico, no espaço projetado embaixo da abertura do mesmo, como ilustrado (em vermelho) em (a) na Fig. 4. A partir do esquema apresentado, foi construído o suporte mecânico em madeira, utilizando quatro potenciômetros lineares como elementos deslizantes, como pode ser observado na Fig. 4 (b).

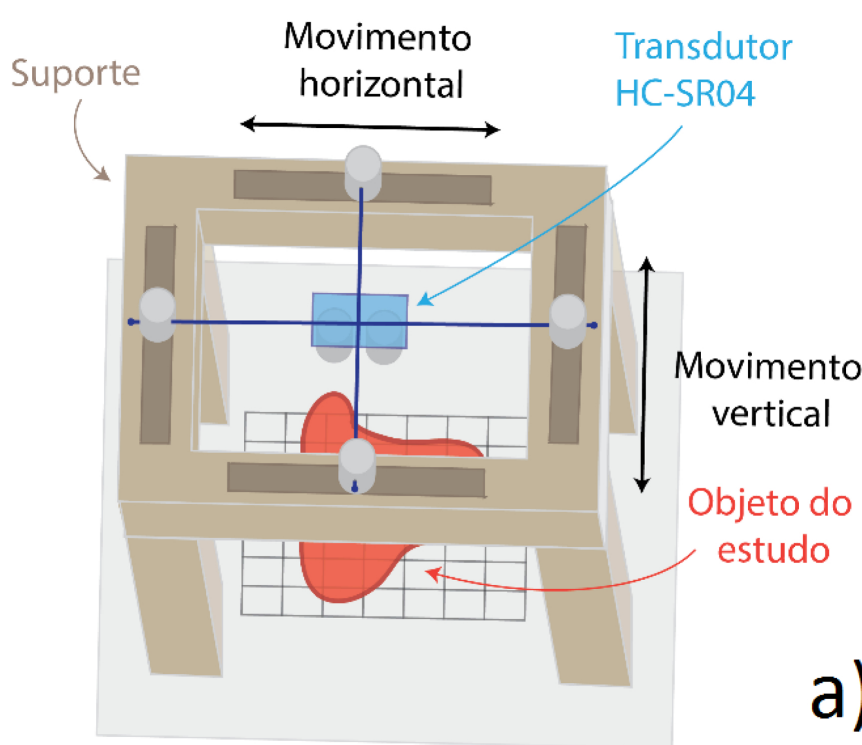

\subsection{Descrição do método de medida com o transdutor}

A medida da distância utilizando o transdutor HC-SR04 pode ser obtida a partir das etapas descritas a seguir ${ }^{3}$

1. Um sinal de Trigger ou gatilho é enviado ao transdutor. Este sinal TTL, que deve ser aplicado no pino Trig do transdutor, deve ter uma duração de, no mínimo, $10 \mu s$.

2. Após o recebimento do sinal de Trigger, o emissor gera um total de 8 pulsos acústicos a uma frequência de $40 \mathrm{kHz}$.

3. Ao mesmo tempo que o primeiro pulso é gerado no emissor, o pino Echo apresenta um valor alto $(+5$ V).

4. Quando a onda emitida encontra um obstáculo, ela é parcialmente refletida, voltando assim para o transdutor. No momento em que a onda refletida chega ao transdutor, ela é reconhecida por uma etapa de filtragem posterior ao sensor, que garante que a onda recebida tenha uma frequência de 40 $\mathrm{kHz}$, e o pino Echo passa a ter um valor Baixo (0 $\mathrm{V})$.

5. O intervalo de tempo em que o pino Echo se manteve em estado Alto $(+5 \mathrm{~V})$ é o tempo transcorrido entre a emissão da onda acústica e o primeiro recebimento da onda refletida pelo sensor. Este é o valor de tempo que pode ser utilizado para calcular a distância entre o transdutor e o obstáculo que refletiu a onda emitida.

O pulso de Echo pode variar de um mínimo de 150 $\mu s$ até um máximo de $25 \mathrm{~ms}$. Caso não exista nenhum obstáculo no caminho da onda emitida (ou a onda se

${ }^{3}$ Para uma descrição mais detalhada sobre o processo de medida da distância com o transdutor HC-SR04, ver [14].

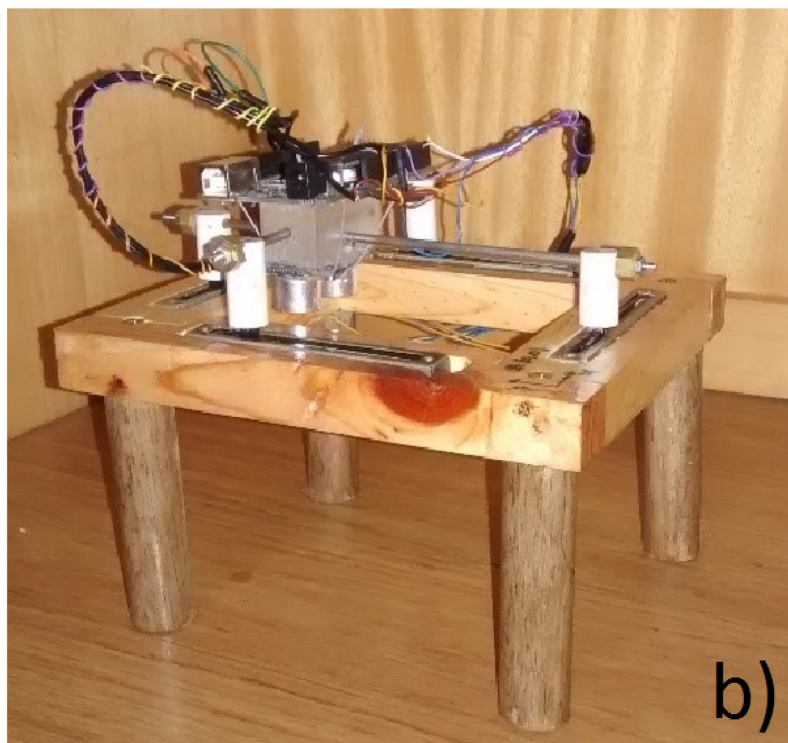

Figura 4: (a) llustração do suporte mecânico projetado para realizar medidas e (b) Imagem do suporte mecânico projetado construído. 
perca no caminho, por algum motivo) o valor obtido de tempo será o máximo especificado pelo fabricante: 38 $m s$.

\subsection{Esquema eletrônico}

O controle do transdutor será realizado pela placa $A r$ duino, a qual gerará os pulsos de Trigger que iniciam o processo de medida de distância, quanto realizará a leitura dessas medidas. A placa Arduino é uma placa controladora utilizada no âmbito eletrônico para controlar processos simples. Ela incorpora, neste modelo, 14 pinos de entradas e saídas digitais TTL e 6 pinos de entradas e saídas analógicas (de $0 \mathrm{~V}$ até $+5 \mathrm{~V}$ ), com conversores analógico-digitais de 10 bits.

Para obter a imagem da superfície medida será realizada uma varredura da superfície (ver Fig. 2 e Fig. 4 ). Cada um dos pontos no qual o sensor esteja localizado medirá um valor de distância do objeto mais próximo. Para controlar a posição do transdutor utilizamos um potenciômetro linear deslizante. Este tipo de potenciômetro, geralmente conhecido como slider, tem um valor de resistência variável em função da posição linear do cabeçote. Os potenciômetros utilizados neste experimento são dois sliders lineares de $330 \mathrm{k} \Omega$. Para determinar o comportamento dos potenciômetros foram realizados testes da resistência em função da posição que mostraram que a relação entre ambos (considerando movimento vertical e horizontal) é linear

A partir dos sliders é possível construir um circuito divisor de tensão que fornecerá um valor de voltagem equivalente à posição linear do cabeçote do potenciômetro. $\mathrm{O}$ valor de voltagem será convertido em um número inteiro de 10 bits pelo conversor analógico-digital (ADC) do Arduino, permitindo assim saber a cada momento a localização aproximada do transdutor tanto no eixo vertical, quanto no horizontal do suporte mecânico. Ambos potenciômetros serão alimentados com uma tensão de +5 $\mathrm{V}$ proveniente do Arduino. Também foi acrescentado um resistor de $220 \Omega$ para garantir a robustez do sistema e evitar possíveis curtos no manuseio do aparelho.

Considerando que o primeiro potenciômetro $\left(R_{1}\right)$ monitora o eixo Horizontal $X$ e o segundo $\left(R_{2}\right)$ o eixo Vertical $Y$, o valor das tensões é dado através dos parâmetros $\alpha$ e $\beta$ segundo (Eq. 3p). Neste cálculo o valor da resistência de $220 \Omega$ foi ignorado. O parâmetro $\alpha$ equivale à porcentagem de deslocamento do cabeçote do slider 1 (de $0 \%$ até $100 \%$ ), da mesma forma que o parâmetro $\beta$ equivale à porcentagem de deslocamento do cabeçote do slider 2 .

$$
\vec{V}=\left(V_{1}, V_{2}\right)=(5 \alpha, 5 \beta)
$$

A partir do valor digital na saída do conversor de 10bits (o que equivale a $2^{10}=1024$ valores possíveis) do Arduino é possível calcular as posições $x$ e $y$ do transdutor, segundo mostrado em (4).

$$
(x, y)=1023(\alpha, \beta)
$$

Por último, o pino Trigger do transdutor será controlado pelo pino digital 8 do Arduino, enquanto que os dados provenientes do pino Echo do transdutor serão lidos pelo pino digital 7 do Arduino. O circuito completo é mostrado na Fig. 5 .

\section{Processamento das medidas}

O processamento das medidas é uma etapa crítica. Nesta fase os valores de entrada devem ser tomados, analisados e filtrados, para finalmente poder obter medidas, e neste caso imagens, que possam ser confiáveis. Este processo foi dividido em três partes (ver Fig. 6), cada uma delas baseada em um mecanismo diferente, em função de seus diversos objetivos:

1. Pré-processamento - Arduino: Nesta etapa o Arduino (para um manual extenso de uso de Arduino e vários exemplos ver 25]) será o responsável por obter as medidas cruas do transdutor (tempo de pulso do Echo), calcular a distância equivalente para essas medidas de tempo, determinar a posição do transdutor no momento em que a medida de distância foi realizada (parâmetros $\alpha$ e $\beta$, dos potenciômetros sliders) e enviar estes valores, um para cada medida realizada, através de uma porta de comunicação, neste caso o USB do Arduino, para serem processados por um PC.

2. HMI e Registro de dados - Labview: Nesta etapa os dados provenientes do Arduino pela porta USB serão recebidos pelo $\mathrm{PC}$ através do software LABVIEW ${ }^{\text {TM }}$ A partir dele será possível visualizar os dados de distância de forma organizada.

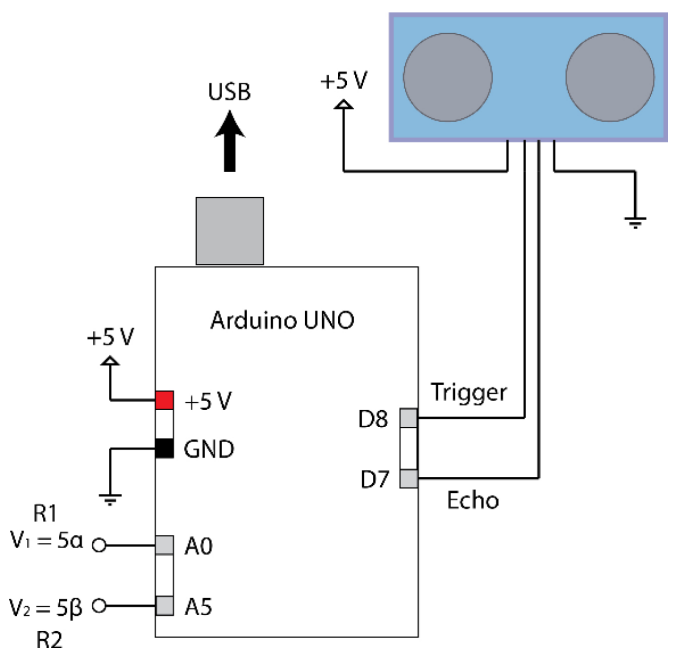

Figura 5: Circuito completo de obtenção de medida de distância.

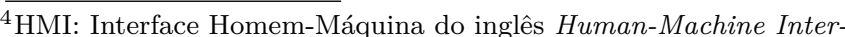
face

${ }^{5}$ É possível, porém, implementar esta etapa em outros programas ou até, inclusive, em código máquina $(\mathrm{C}, \mathrm{C}++$,etc. $)$. Neste projeto o LABVIEW foi utilizado por sua versatilidade e facilidade de uso, assim como a disponibilidade de acesso ao mesmo. 


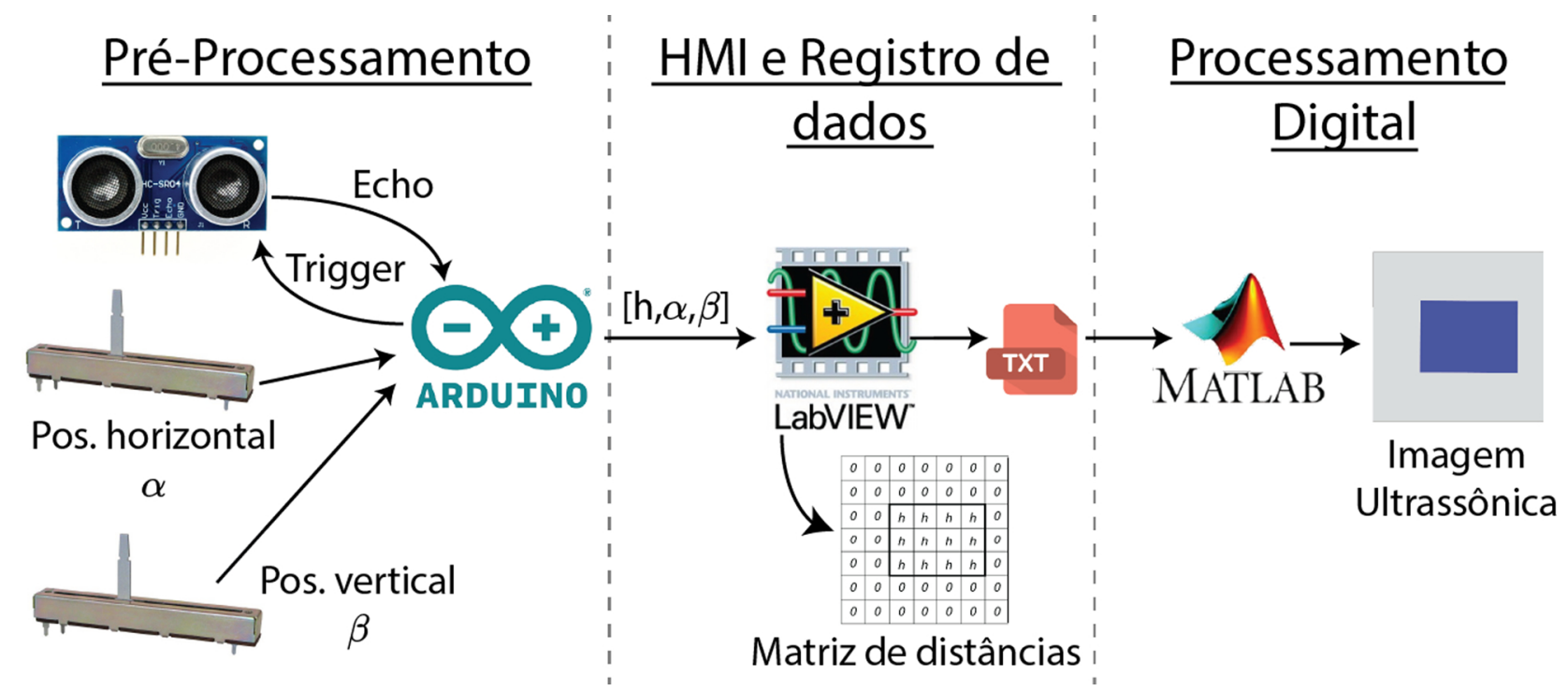

Figura 6: Esquema das etapas de processamento das medidas de distância.

No Labview o usuário poderá estabelecer as dimensões da imagem final desejada (por exemplo, $1024 \times 1024$ ou $16 \times 16$ ) e os dados obtidos serão mostrados ao usuário. Este último passo é crucial, já que a matriz (equivalente à imagem que será gerada posteriormente) é mostrada ao usuário inicialmente como uma matriz de zeros. Como o usuário deverá varrer toda a superfície de medida com o transdutor, é possível saber quais pontos ainda não foram varridos pelo sensor simplesmente procurando por aquelas celas que ainda contém valores nulos. No processo de varredura da área, a matriz é atualizada e cada posição é preenchida pelo valor da distância medida pelo transdutor para esse ponto. O usuário realiza as medidas varrendo linha por linha, ou coluna por coluna, ao mesmo tempo que observa a matriz sendo preenchida, de forma que o processo de medida é controlado pelo próprio usuário. Também nesta etapa, uma vez preenchida toda a matriz, o usuário pode salvar a mesma em um arquivo de texto que será a base para o processamento final.

3. Processamento digital - MATLAB: Por último, após a obtenção das medidas em um arquivo de texto, o software MATLAB $^{\mathrm{TM}}$ deverá importar estes dados e realizar diversas operações de processamento digital para obter as imagens ultrassônicas desejadas. Além destas imagens, o MATLAB $^{\mathrm{TM}}$ também permite realizar operações como segmentação, que permitirão derivar parâmetros secundários como área, centroide ou orientação dos objetos segmentados. Todos estes processos são discutidos nesta seção.

\subsection{Etapa de Pré-processamento - Arduino}

Nesta etapa o Arduino é o responsável por obter as medidas do transdutor e enviá-las via canal de comunicação USB para o PC.

Após o processo de obtenção da medida, descrito na seção 3.3. é necessário fechar a porta de comunicação aberta anteriormente para permitir que a mesma seja ocupada por outros elementos que possam necessitá-la.

Ao longo deste processo, também é necessário estabelecer um protocolo de comunicação que será utilizado para enviar os dados das medidas através do canal de comunicação USB até o Labview, no PC. Este protocolo, criado exclusivamente para esta aplicação, contém um primeiro caractere "s" de start, que indica o início de uma nova mensagem, é seguido do valor do parâmetro $\alpha$ (posição horizontal do transdutor), o parâmetro $\beta$ (posição vertical do transdutor) e um caractere "e" de finalização da mensagem. Este protocolo pode ser observado na Fig. 7

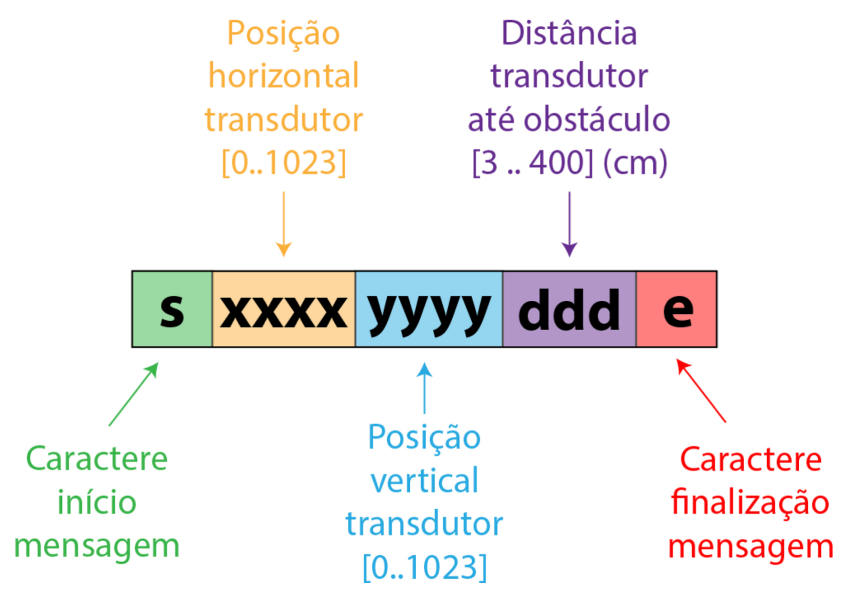

Figura 7: Protocolo de mensagem utilizado na comunicação pelo USB entre o Arduino e o PC (Labview). 


\subsection{HMI ${ }^{4}$ e Registro de Dados}

\subsubsection{Resolução da Imagem Digital}

Para poder implementar um algoritmo que construa uma imagem digital a partir de medidas de uma magnitude contínua é necessário discretizar essa mesma magnitude. Esta discretização implica a criação de porções de área projetada em uma superfície, definindo assim uma resolução. Cada uma destas porções de área será interpretada, no final, como um pixel na imagem ultrassônica. Cada posição da nossa imagem ultrassônica final poderá ser localizada segundo dois índices, que chamaremos $i$ e $j$, sendo $i$ o índice equivalente às filas da imagem e $j$ o índice equivalente às colunas da mesma. Cada elemento desta imagem será equivalente a uma região da superfície real analisada pelo transdutor.

Como a medida de localização dos parâmetros $\alpha$ e $\beta$ dos potenciômetros é obtida pelas entradas analógicas do Arduino, e como estas entradas têm conversores de 10 bits, a medida de posição será um número inteiro que terá um valor entre 0 e 1023 , sendo 0 o valor equivalente à posição $0 \%$ do cabeçote e 1023 à posição $100 \%$. Se este valor não for alterado, a nossa matriz de medidas finais terá um tamanho de $1024 \times 1024$, já que haverá 1024 posições diferentes que cada um dos potenciômetros poderá tomar.

A precisão do sistema de localização do transdutor utilizado neste projeto não tem uma resolução tão alta quanto a escala dos potenciômetros. Assim, ainda que o Arduino seja capaz de medir 1024 valores diferentes de localização, os potenciômetros não entregam 1024 valores bem definidos em sua escala dinâmica. Mesmo com o cabeçote parado em uma posição constante, o valor de resistência equivalente nesse ponto sofre flutuações mecânicas, de forma que a medida de posição para um mesmo ponto é instável.

A resolução do próprio transdutor logicamente também afeta na resolução da imagem final. O ângulo de abertura do sensor utilizado influencia no espalhamento das ondas emitidas e, portanto, na área do obstáculo que será enxergada pelo mesmo. Quanto maior este ângulo, menor a resolução da medida. O estudo da resolução de medida para as condições do aparelho montado e o transdutor utilizado é descrito na seção 4.3 A partir do mesmo, foi determinado que a distância linear mínima entre cada ponto (pixel) deveria ser de $2,6 \mathrm{~cm}$.

Existe, ainda, um último fator que determina a resolução na medida da localização do transdutor: o atrito do potenciômetro. Os potenciômetros utilizados neste trabalho não são de alta resolução, logo apresentam um certo atrito no movimento, causando ainda mais perda de resolução no movimento do cabeçote.

Considerando todos estes fatores e incluindo o tempo necessário para obter a medida definimos um valor que evitava as oscilações no valor de posição, diminuía o efeito do atrito do potenciômetro, era compatível com a resolução de uma mão humana e ainda permitia realizar medidas em um tempo máximo de 5 minutos por objeto escaneado. A resolução definida foi de $16 \times 16$ pixels.

\subsection{2. $\mathrm{HMI}^{4}$ - Labview}

O Labview foi introduzido como etapa prévia ao pro-

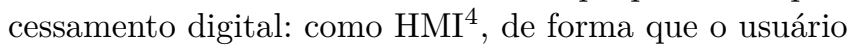
fosse capaz de controlar este processo.

Os dados de cada medida realizados pelo Arduino deverão ser lidos pela porta USB a fim de serem mostrados ao usuário de forma ordenada. No painel do Labview deverá aparecer a matriz de distâncias final. Cada medida lida pelo Labview conterá a informação da medida de distância para uma certa localização do transdutor, assim esta medida será colocada na cela da matriz de distâncias correspondente à posição na qual se encontrava o transdutor ao realizar esta medida.

No entanto, como discutido no item anterior, a imagem final terá uma resolução limitada de $16 \times 16$, de forma que, na verdade, os valores de localização (parâmetros $\alpha$ e $\beta$ ) do transdutor deverão ser convertidos em novos valores equivalentes da matriz de distâncias.

\subsection{Discussão da mínima superfície mensurável}

Nesta seção iremos discutir qual é a área da menor superfície sensível ao transdutor. Para isso, definimos o ângulo de abertura do sensor $\Lambda$ (Fig. 8), que é o ângulo máximo de espalhamento das ondas conforme avançam na direção de propagação, e está diretamente relacionado à área do ângulo sólido da própria onda. No caso do transdutor, podemos realizar a suposição de que o foco é um ponto único que se encontra no próprio foco do emissor do transdutor. Consideramos um obstáculo na direção de propagação das ondas, cujo centro esteja localizado na mesma vertical que o centro do transdutor 6 Neste caso, se as ondas ultrassônicas se deparassem com um obstáculo de comprimento $c$, a uma distância vertical $d$ do transdutor e a uma distância horizontal $b$ do centro do emissor, pela lei da reflexão todo ponto sobre a superfície do obstáculo no qual incida uma onda ultrassônica se torna um novo foco agora se propagando em direção ao transdutor.

Considerando a origem como o centro do sensor, podemos estabelecer que, se situando o centro do obstáculo na mesma vertical que o centro do transdutor, haverá dois pontos essenciais na geometria do mesmo: o ponto a menor distância horizontal do foco de emissão (A) e o ponto a maior distância horizontal do foco (B). Podemos estabelecer, agora, que se ambos pontos A e B se encontram em uma posição tal que seus respectivos ângulos até o foco estão contidos entre $[-\Lambda / 2, \Lambda / 2]$, então qualquer

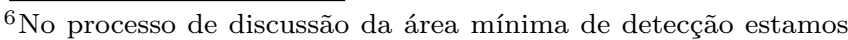
considerando que o obstáculo se encontra na posição ótima para realizar esta detecção. Se o obstáculo se encontra em qualquer outro lugar que não seja o ponto ótimo a área mínima mensurável será menor (até que, no caso infinito, a área mínima mensurável seja $\infty)$.
} 


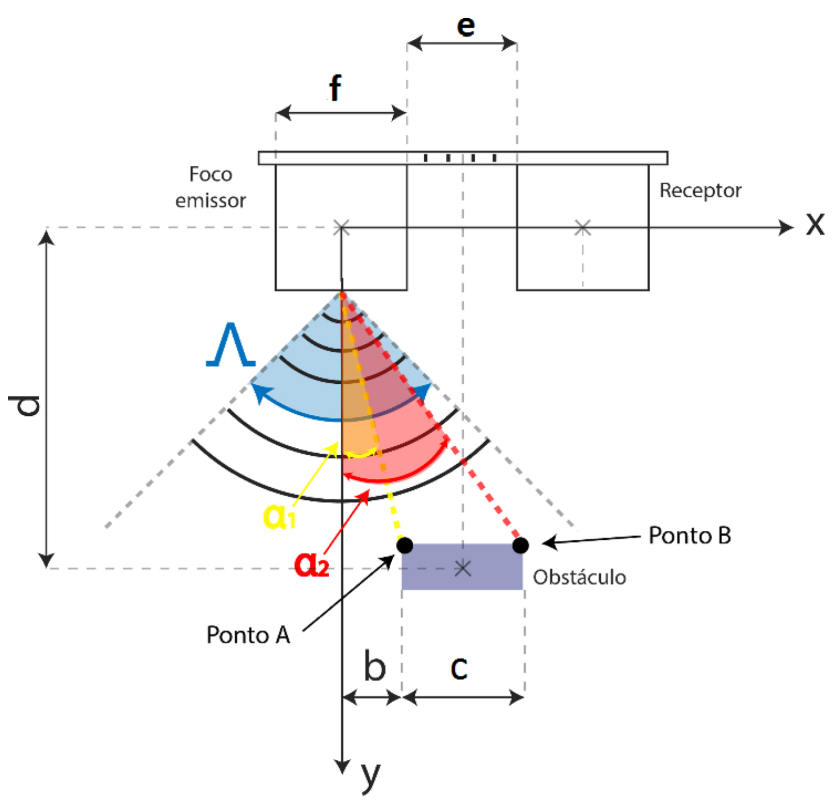

Figura 8: Ilustração do esquema de reflexão para um obstáculo não-pontual.

ponto entre eles também estará contido nesse intervalo, sempre que a distância na superfície seja constante.

Para o caso mostrado na Fig. 8, os valores do ângulo entre o centro do sensor e o ponto A, $\alpha_{1}$, e entre o centro do sensor e o ponto $\mathrm{B}, \alpha_{2}$, são dados pelas equações (5) e 6):

$$
\begin{gathered}
\alpha_{1}=\arctan \frac{b}{d} \\
\alpha_{2}=\arctan \frac{b+c}{d}
\end{gathered}
$$

Estes ângulos devem estar dentro do intervalo $[-\Lambda / 2, \Lambda / 2]$, o que leva as seguintes condições limite:

$$
\begin{gathered}
\left(\frac{-\Lambda}{2} \leq \alpha_{1} \leq \frac{\Lambda}{2}\right) \rightarrow \tan \frac{-\Lambda}{2} \leq \frac{b}{d} \leq \tan \frac{\Lambda}{2} \\
\left(\frac{-\Lambda}{2} \leq \alpha_{2} \leq \frac{\Lambda}{2}\right) \rightarrow \tan \frac{-\Lambda}{2} \leq \frac{b+c}{d} \leq \tan \frac{\Lambda}{2} .
\end{gathered}
$$

As condições anteriores mostradas na equação (7) e na equação (8) devem ser cumpridas para que o obstáculo seja atingido pela onda emitida pelo receptor. Entretanto, estas condições não são suficientes para assegurar que as ondas refletidas pelo transdutor cheguem até o receptor e, por tanto, que a medida de distância possa ser realizada.

Para isso, analisamos o que acontece no caso da reflexão das ondas no obstáculo, para encontrar as condições limites nas quais a onda refletida chega ao receptor. Porém, somente é necessário conhecer quais são esses ângulos em 2 casos extremos: considerando qual é o ângulo mínimo para que as ondas refletidas no ponto A (Fig. 8 incidam no ponto C (Fig. 9) e qual o ângulo máximo para que as ondas refletidas no ponto B (Fig. 8 incidam no ponto D (Fig. 9).

Sabendo que o ângulo de incidência no obstáculo é o mesmo do ângulo de reflexão, é possível observar que o processo de reflexão seguiria segundo a ilustração da Fig. 9 sendo o ponto $\mathrm{C}$ o ponto do receptor mais próximo, na horizontal, do foco do emissor, e o ponto $\mathrm{D}$ o ponto do receptor mais afastado, na horizontal, do foco do emissor.

A partir da ilustração da Fig. 9 e a partir da condição do ângulo de abertura máximo, é possível obter as condições de intervalo para os valores dos ângulos de reflexão dos pontos A e B, como mostrado na equação (9) e na equação 10 .

$$
\begin{gathered}
\tan \frac{-\Lambda}{2} \leq \frac{e+\frac{f}{2}-b}{d} \leq \tan \frac{\Lambda}{2} \\
\tan \frac{-\Lambda}{2} \leq \frac{e+\frac{3 \cdot f}{2}-b-c}{d} \leq \tan \frac{\Lambda}{2}
\end{gathered}
$$

Considerando o centro do obstáculo na mesma vertical do centro do transdutor. Neste caso o valor de $b$ pode ser calculado por

$$
b=\frac{(e+f-c)}{2}
$$

Utilizando as condições anteriores mostradas nas equações (7 8 9 e 10), introduzindo a condição da localização ótima da equação (11) obtemos:

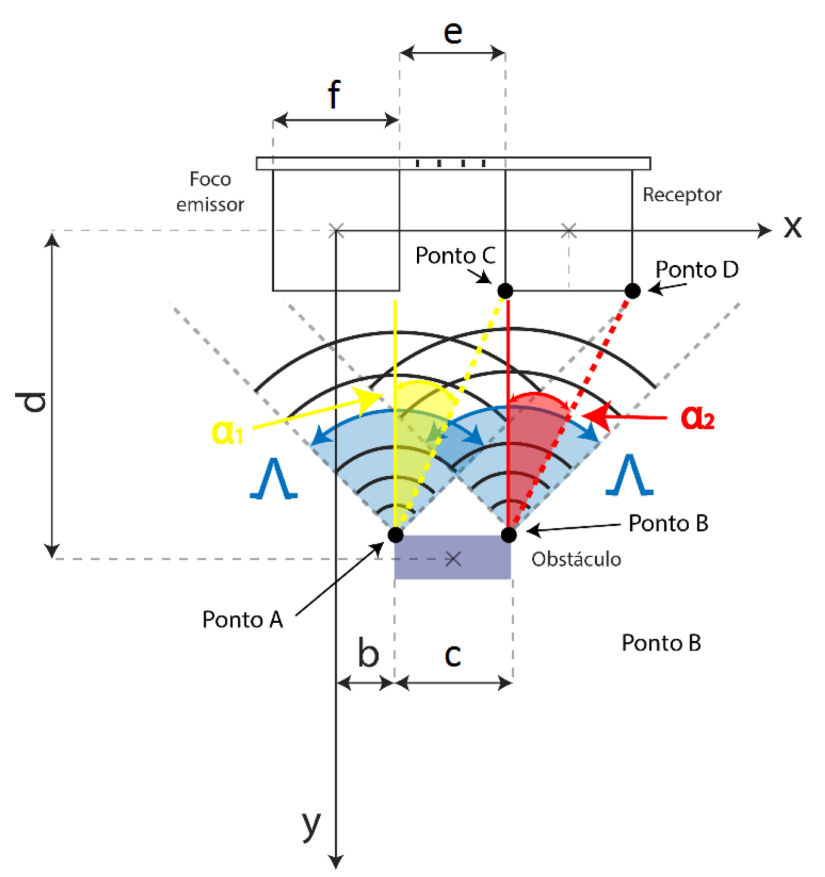

Figura 9: Ilustração do esquema de reflexão e incidência no receptor para um obstáculo não-pontual. 


$$
\left\{\begin{array}{l}
\left(e+f-2 d \tan \frac{\Lambda}{2}\right) \leq c \leq\left(e+f+2 d \tan \frac{\Lambda}{2}\right) \\
\left(-e-2 d \tan \frac{\Lambda}{2}\right) \leq c \leq\left(2 d \tan \frac{\Lambda}{2}-e\right) \\
\left(-e-f-2 d \tan \frac{\Lambda}{2}\right) \leq c \leq\left(-e-f+2 d \tan \frac{\Lambda}{2}\right) \\
\left(e+2 f-2 d \tan \frac{\Lambda}{2}\right) \leq c \leq\left(e+2 \cdot f+2 d \tan \frac{\Lambda}{2}\right)
\end{array}\right\}
$$

Considerando estas últimas e forçando a condição $c \geq 0$ obtemos:

$$
c \geq e+2 f-2 d \tan \frac{\Lambda}{2} .
$$

Conhecendo o valor da separação entre emissor e receptor $(e=1 \mathrm{~cm})$, o valor do diâmetro do receptor e do emissor $(f=1,6 \mathrm{~cm})$, o valor do ângulo de abertura do sensor 14$]\left(\Lambda \simeq 30^{\circ}\right)$ e sabendo que a distância mínima que o sensor consegue medir é de $3 \mathrm{~cm}$, é possível calcular o valor de $c$, isto é, o menor comprimento resolvido pelo aparato dado a menor distância ao alvo, a partir da equação 13 :

$$
c \geq 2,59 \mathrm{~cm} \text {. }
$$

É importante ressaltar que este limite trata-se apenas de um limite geométrico, e quanto maior for a distância do alvo, menor ele será. Na prática outros fatores limitarão a resolução a medida que a distância $d$ aumenta, como a intensidade do sinal recebido.

Supondo que as mesmas equações são aplicáveis obtemos que o valor mínimo de área detectável, para distância do alvo ao transdutor $d=3 \mathrm{~cm}$

$$
S_{\text {min }}=c^{2}=6,72 \mathrm{~cm}^{2}
$$

\subsection{Etapa de Processamento Digital (MATLAB)}

A tarefa implementada no MATLAB é a de, a partir da matriz de distância redimensionada gerada pelo Labview (Fig. 6 ), processar esses dados, aplicar filtros sobres eles e gerar as imagens ultrassônicas, assim como extrair informações relevantes das superfícies escaneadas.

Para melhorar a qualidade das imagens obtidas iremos definir uma Função de Espalhamento do Ponto ("Point Spread Function", doravante PSF) para o instrumento [26]. Esta função representa a resposta do sistema a uma entrada pontual.

A PSF atua nas imagens obtidas como um filtro. A aplicação de um filtro $h$ representando a PSF sobre uma imagem $u$ produz uma imagem $v$ resultado da operação de convolução 27]:

$$
v=u * h .
$$

Conhecendo o filtro $h$ é possível deconvoluir, isto é, remover o efeito da PSF, a imagem obtida pelo aparelho. Os detalhes deste processo e os resultados da PSF obtida são descritos na seção 5 .
Por último é necessário identificar os objetos, logo realizamos um processo de segmentação MultiThreshold (Método Otsu), capaz de segmentar a imagem a partir de mais de um nível de limiar do tom de cinza da imagem original 28]. O MATLAB incorpora uma função que permite segmentar uma imagem utilizando este método: a função imquantize. Por outro lado, a função regionprops do MATLAB também permite calcular propriedades interessantes dos objetos na imagem segmentada, como área, centroide, etc.

\section{Medidas Experimentais}

\subsection{Erro nas medidas de distância}

Para estimar o erro nas medidas da distância variamos a posição entre o transdutor e vários obstáculos desde um mínimo de $3 \mathrm{~cm}$ até um máximo de $22 \mathrm{~cm}$. Mediante a utilização de uma régua, foi registrado o valor de referência no qual o obstáculo se encontrava e o valor medido pelo transdutor. Foram testadas três superfícies de argila, alumínio e madeira, respectivamente.

Foi possível observar que os erros relativos (com relação à distância de referência indicada pela régua) para cada tipo de material foram menores que $5 \%$ para argila e para madeira e menor que $7 \%$ para o alumínio em todo o intervalo testado. A distância que apresentou menor erro relativo para argila e madeira foi de aproximadamente 13 $\mathrm{cm}$. Portanto, o suporte mecânico foi construído com uma altura (do transdutor até a mesa, ou o suporte inferior) compatível com essa medida de mínimo erro.

\subsection{Obtenção da PSF do Aparelho}

Para caracterizar a PSF foi realizado um primeiro escaneamento de um objeto com projeção 2D pontual, isto é, um cilindro com comprimento muito superior ao diâmetro. A área superficial da base deste cilindro é de $7 \mathrm{~cm}^{2}$, de forma que é superior à área mínima detectável, em teoria, pelo transdutor, segundo explicado na seção 4.3. Em princípio, o objeto deveria ser representado na imagem obtida como um ponto ou um círculo de raio pequeno.

A imagem obtida para o objeto pontual é mostrada na Fig. 10(a). Como é possível observar na mesma, o objeto pontual não foi representado de forma fiel pelo instrumento. Esta imagem pode ser considerada, por outro lado, como uma PSF inicial do aparelho. Utilizando um processo de deconvolução [29] é possível recuperar uma aproximação mais próxima à PSF real do instrumento a partir da primeira aproximação da mesma. Esta PSF real é mostrada na Fig. 10 (b).

\subsection{Resultados experimentais para Objeto 1 (Dado)}

O primeiro elemento utilizado como objeto para ser escaneado e testar o aparelho foi um dado. O dado utilizado, 

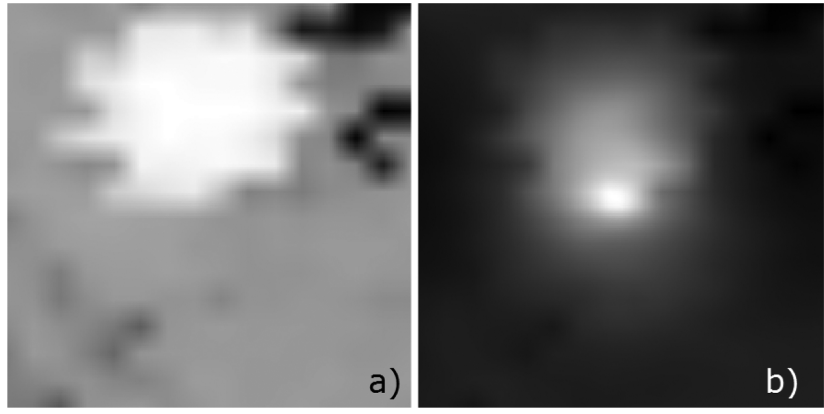

Figura 10: (a) Imagem do objeto pontual utilizado para determinar a PSF do instrumento. (b) Essa imagem pode ser considerada a PSF inicial do aparelho.

com uma área superficial do topo de aproximadamente 9 $\mathrm{cm}^{2}$ e uma altura de $3 \mathrm{~cm}$, é mostrado na Fig. 11 .

Após realizar as medidas foi obtido, utilizando MATLAB, a imagem em tons de cinza tanto dos dados crus quanto dos dados filtrados (deconvolução da PSF), ambas mostradas na Fig. 12

A imagem segmentada, depois de ser filtrada com a PSF, é mostrada na Fig. 13 (a), junto com uma superposição da segmentação e a imagem original (b).

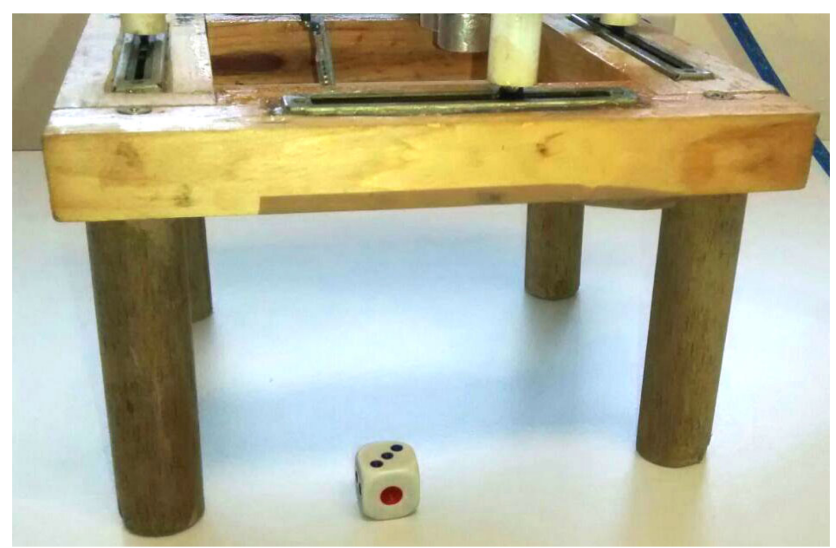

Figura 11: Dado utilizado no primeiro experimento de obtenção de imagem ultrassônica.
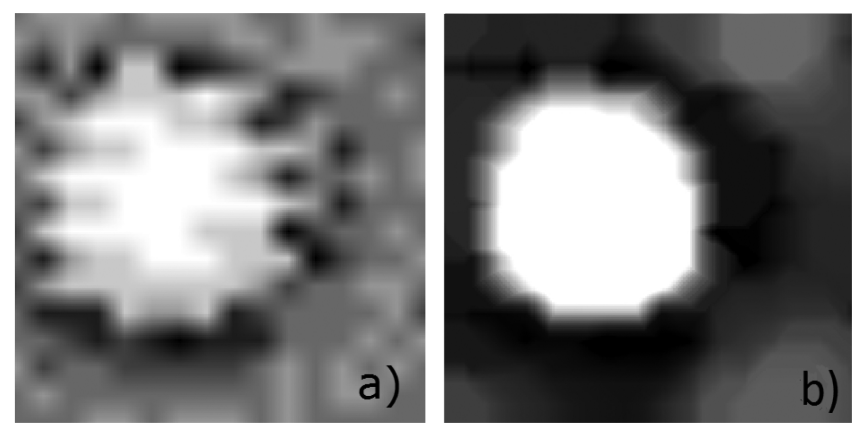

Figura 12: (a) Imagem ultrassônica em tons de cinza dos dados originais, sem filtro. (b) Imagem ultrassônica em tons de cinza dos dados filtrados com a PSF.
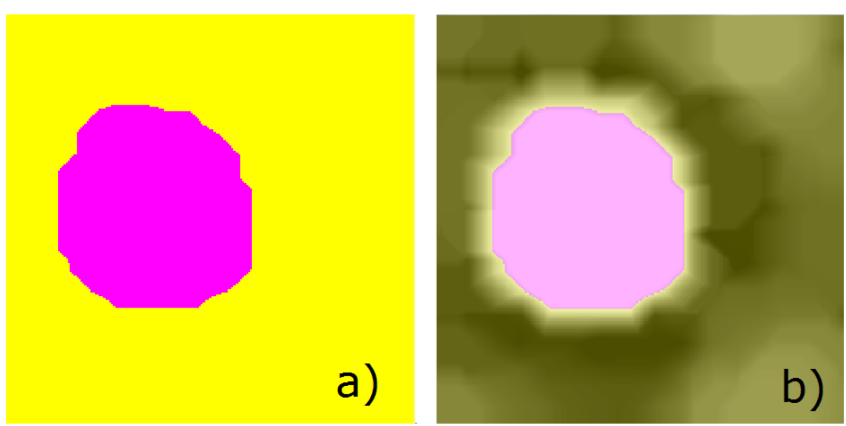

Figura 13: (a) Imagem ultrassônica segmentada dos dados filtrados. (b) Superposição da imagem original filtrada e a segmentação.

A partir da imagem, determinamos a área do topo do objeto e a altura do objeto, enquanto que os valores de referência foram definidos com o auxílio de uma régua. A área da figura segmentada no MATLAB é calculada em número de pixels. $\mathrm{O}$ aparelho escaneia uma superfície total de $7 \times 7(\mathrm{~cm} \times \mathrm{cm})=49 \mathrm{~cm}^{2}$. Sabendo que o número de pixels total nessa área (imagem), após ser reescalada para poder ser manipulada mais facilmente, é de $200 \times 200(p x \times p x)=40000 p x^{2}$, é possível calcular a área real do objeto segmentado $\left(\mathrm{em} \mathrm{cm}^{2}\right)$ a partir do número de pixels do objeto segmentado, como mostrado na equação (17). Estes parâmetros são apresentados na Tabela 3

$$
S_{r}=\left(\frac{7}{200}\right)^{2} \cdot n_{\text {pixels }}
$$

A partir dos resultados mostrados na Tabela 3 notamos que o erro na altura ficou dentro do limite de desvio estabelecido comentado na seção 5.1. É importante ressaltar que a medida da área depende de uma boa segmentação, entretanto ainda que, de forma empírica, visualmente a forma do objeto não esteja claramente definida como um quadrado, o erro relativo na área foi menor do que $7 \%$.

\subsection{Resultados experimentais para Objeto 2 (Lata)}

Como um segundo teste experimental utilizamos uma lata de verniz com uma área superficial de aproximadamente $24,54 \mathrm{~cm}^{2}$ e uma altura de 7,00 cm, mostrada na Fig. 14

As medidas de altura e área foram obtidas partir do processamento de sinais e imagens nos dados filtrados (incluindo deconvolução da PSF), como no caso anterior. Ambas imagens são mostradas na Fig. 15. A imagem segmentada, após ser filtrada com a PSF é mostrada na

Tabela 3: Parâmetros de qualidade da medida do Objeto 1

\begin{tabular}{lccc}
\hline & Medida & Real & Desvio (\%) \\
\hline Altura $(\mathrm{cm})$ & 2,864 & 3,0 & 4,53 \\
Área superficial $\left(\mathrm{cm}^{2}\right)$ & 9,6273 & 9,0 & 6,97 \\
\hline
\end{tabular}




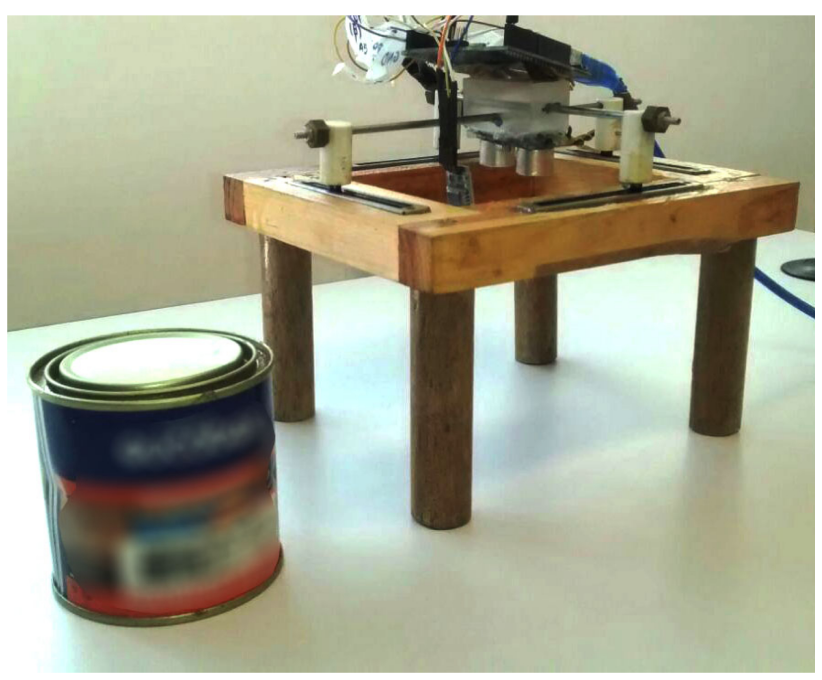

Figura 14: Lata de verniz utilizada no segundo experimento de obtenção de imagem ultrassônica.
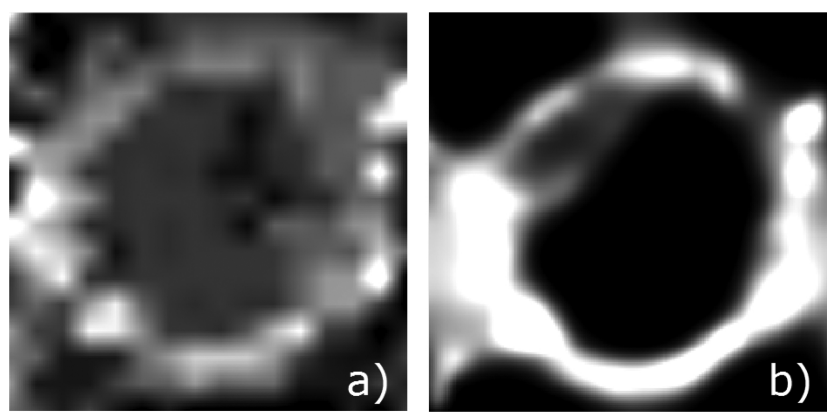

Figura 15: (a) Imagem ultrassônica em tons de cinza dos dados originais, sem filtro. (b) Imagem ultrassônica em tons de cinza dos dados filtrados com a PSF.
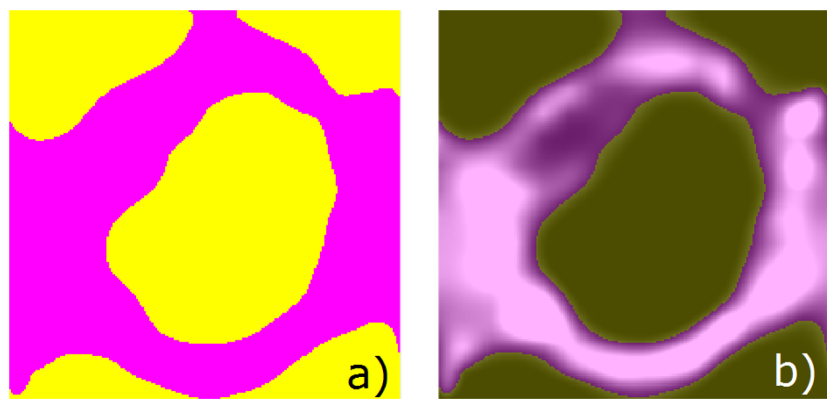

Figura 16: (a) Imagem ultrassônica segmentada dos dados filtrados. (b) Superposição da imagem original filtrada e a segmentação.

Fig. 16 (a), junto com uma superposição da segmentação e a imagem original (b). Os parâmetros de qualidade para esta medida, a partir da equação (17), são apresentados na Tabela 4

A partir dos resultados mostrados na Tabela 4 observamos que o desvio na altura foi um pouco superior ao esperado, que era menor que 5\%. Entretanto ainda é um erro de menos de $0,5 \mathrm{~cm}$, perfeitamente compatível para aplicações didáticas e de demonstração de conceito. Por
Tabela 4: Parâmetros de qualidade da medida do Objeto 2

\begin{tabular}{lccc}
\hline Lata (Externa) & Medida & Ref. & Desvio (\%) \\
\hline Altura $(\mathrm{cm})$ & 6,571 & 7,00 & $6,13 \%$ \\
Área superficial $\left(\mathrm{cm}^{2}\right)$ & 23,837 & 24,54 & 2,86 \\
\hline
\end{tabular}

outro lado, a medida da área teve um desvio menor que $3 \%$.

\section{Aplicações no ensino de física}

A montagem experimental proposta foi construída com um orçamento total menor do que 80 reais. Este tipo de experimento pode ser explorado de diversas maneiras, tanto no ensino médio, quanto no ensino superior dependendo dos recursos disponíveis e dos objetivos particulares. Na análise apresentada, utilizamos MATLAB e o Labview, que são softwares normalmente disponíveis para alunos do ensino superior. Estes foram escolhidos devido à praticidade de utilização nas operações realizadas, entretanto podem ser facilmente substituídos por softwares livres. O MATLAB poderia ser substituido pelo software livre GNU Octave, por exemplo; enquanto que a etapa de processamento implementada em Labview poderia ser facilmente implementada em $\mathrm{C}, \mathrm{C}++$, Qt ou mesmo no próprio programa carregado no Arduino.

No ensino médio é possível realizar demonstrações didáticas, tanto em sala de aula, como em feiras de ciências. Com auxílio do docente, por exemplo, os alunos poderiam gerar as suas próprias imagens e calcular a distância com relação a obstáculos. Em geral, os estudantes têm o interesse em perceber como as formas dos objetos cotidianos se apresentam diante do ultrassom, e isso pode ser utilizado para que os mesmos utilizem softwares de processamento de imagens a escolha deles para obter as dimensões dos objetos através das imagens. Caso não haja recursos computacionais disponíveis, isso pode ser feito até mesmo de maneira manual. Como a resolução do equipamento não é alta, pode ser feita também uma discussão qualitativa sobre os erros nas medidas.

No ensino superior, ou ainda, no ensino médio dentro de uma perspectiva interdisciplinar STEM [30] (i.e., que vise integrar o ensino das disciplinas de ciência, tecnologia, engenharia e matemática) é possível promover a construção da montagem junto com estudantes. Nesta perspectiva os alunos aprenderão conceitos de eletrônica, circuitos e eletricidade, além dos já citados princípios de acústica do ultrassom. Para esse tipo de estudo as análises realizadas em 4.3 poderiam ser feitas considerando outros alvos em posições diferentes, como um exercício. Se o grupo de estudantes tiver o interesse em eletrônica, o projeto pode ser facilmente adaptado para utilizar motores elétricos que podem realizar as medidas automaticamente. Caso o foco seja em aulas que integrem conceitos de computação e programação, é possível utilizar a aquisição de imagens para motivar o desenvolvimento de um software de visu- 
alização. No presente momento, estamos trabalhando no desenvolvimento de aplicativo para celular 7 (Android), com o que pretendemos que o experimento fique ainda mais acessível e independente de outros programas.

\section{Conclusões e Perspectivas futuras}

Nesta contribuição apresentamos um arranjo experimental capaz de gerar imagens de ultrassom e extrair atributos destas imagens. O aparato experimental possui um potencial didático interessante. Ele pode ser utilizado em diversos experimentos demonstrativos tanto de forma qualitativa quanto de forma quantitativa. Por sua simplicidade, o equipamento pode ser construído sob supervisão de um docente. Igualmente, pode ser utilizado como uma demonstração de conceito e aplicação tecnológica de física no contexto das aulas de ondas sonoras no ensino médio, ilustrando os conceitos de funcionamento de outros equipamentos como sensores de estacionamento e aparelhos de ultrassom na medicina. Os códigos utilizados nesta contribuição poderão ser fornecidos a interessados mediante pedido e autorização dos autores.

O desvio nas medidas de distância nos dois objetos testados neste trabalho foi de, respectivamente, aproximadamente $5 \%$ e $7 \%$ o que equivale a um erro absoluto de cerca de $0,28 \mathrm{~cm}$, para ambos os casos. Este valor, que está de razoável acordo com a resolução da medida de distância indicada pelo fabricante no manual do transdutor 1 indica a resolução máxima que pode ser obtida das medidas extraídas das imagens ultrassônicas realizadas.

Em relação às medições de área derivadas das imagens obtidas, o erro médio nas mesmas foi de $3 \%$ e $5 \%$, respetivamente, o que é equivalente a um erro absoluto médio de cerca de $0,66 \mathrm{~cm}^{2} \approx(0,81 \mathrm{~cm})^{2}$. Este erro é superior ao especificado pelo fabricante, e pode estar relacionado ao processo de segmentação ou de obtenção/aplicação da PSF na etapa de processamento.

As imagens obtidas a partir do experimento, embora com resolução limitada, permitem ter uma ideia do objeto capturado, assim como obter medidas físicas de suas características (como distância, área, orientação, centroide, etc.) que, mesmo apresentando um desvio considerável, podem, em principio, ser utilizadas na caracterização de obstáculos.

A obtenção da PSF do transdutor segundo o método explicado na seção 5.2 permitiu, quando aplicado às imagens, melhorar a qualidade visual das mesmas, reduzindo o ruído e evidenciando assim mais claramente a estrutura do objeto capturado (Fig. 15), ao mesmo tempo que facilitou o processo de segmentação.

Visando perspectivas futuras, poderia se enriquecer o potencial demonstrativo da montagem com a implementação de um sistema de obtenção de imagens a partir de medidas de impedância acústica. Desta forma, ao invés de utilizar o tempo de trânsito como medida, a variação

7 versão preliminar disponível em: https://github.com/ brunocalou/ultrasonic-graph entre a potência da onda emitida e a potência da onda refletida seria utilizado para obter informações relevantes sobre o material e a textura do obstáculo, assim como utilizado na obtenção de imagens ultrassônicas de poço de reservatório (ver exemplo na Fig. 1).

Outra melhoria a ser aplicada, seria a implementação de um sistema automático de deslocamento do sensor e captação de dados através de motores passo-a-passo, por exemplo, o que não só facilitaria o processo de obtenção de imagens, mas também incrementaria a resolução espacial da medida. Devido à precisão dos motores, seria possível aumentar a resolução da própria imagem.

Por último, a inclusão de sensores de temperatura, umidade e pressão permitiria realizar uma estimativa mais real dos valores de velocidade do som no meio, para condições específicas do ambiente, permitindo assim aumentar a fidelidade e precisão das medidas de distância realizadas.

\section{Agradecimentos}

Os autores gostariam de agradecer J. Coelho por sugestões e texto. C.R. Bom gostaria de agradecer ao CNPQ pelo apoio. Os autores também gostariam de agradecer a colaboração com a Petrobrás, que inspirou o desenvolvimentos deste trabalho. M.B. Valentín gostaria de agradecer ao professor Geraldo Cernicchiaro pelas sugestões e discussões.

\section{Material Suplementar}

O seguinte material suplementar está disponível online: Apêndice

\section{Referências}

[1] Ministério da Educação, Parâmetros Curriculares Nacionais: Ensino Médio - Ciências da Natureza, Matemática e suas Tecnologias (Mec/Sentec, Brasília, 2000), disponível em http://portal.mec.gov.br/seb/arquivos/ pdf/ciencian.pdf acessado em 22/6/2017.

[2] Marcos José Chiquetto, Revista e-Curriculum, 7, 1 (2011)

[3] Mauro Sérgio Teixeira de Araújo e Maria Lúcia Vital dos Santos Abib, Revista Brasileira de Ensino de Fisica 25, 176 (2003).

[4] Carlos Eduardo Laburú, Investigações em Ensino de ciências 10, 161 (2016).

[5] I Wendelhag, T Gustavsson, M Suurküla, G Berglund, and J Wikstrand, Clinical Physiology and Functional Imaging 11, 565 (1991).

[6] William C Cummings, Transactions of the American Fisheries Society 92, 178 (1963).

[7] Brian Bingham, Brendan Foley, Hanumant Singh, Richard Camilli, Katerina Delaporta, Ryan Eustice, Angelos Mallios, David Mindell, Christopher Roman, and Dimitris Sakellariou, Journal of Field Robotics 27, 702 (2010). 
[8] Akamatsu Yusei and Prigogine Naoyuki, Japanese Society of Fisheries 59, 1297 (1993).

[9] JW Wladimiroff, HM Tonge and PA Stewart, BJOG: An International Journal of Obstetrics \& Gynaecology, 93, 471 (1986).

[10] Isabel M Ramos, KJ Taylor, Ruben Kier, Peter N Burns, Daniel P Snower and Darryl Carter Radiology 168, 633 (1988).

[11] AJ Hayman, Philippe Parent, Philip Cheung, Patrick Verges, et al., SPE production \& Facilities, 13, 5 (1998).

[12] JC Lofts and LT Bourke, Geological Society 159, 59 (1999).

[13] Ubi Solutions, Schulemberger Brochures (Ubi Solutions, Gennevilliers, 2015).

[14] Cytron Technologies, Product User's Manual - hc-sr04 Ultrasonic Sensor (Cytron Technologies, Pulau Pinang 2013).

[15] Marcus Varanis, Anderson Langone Silva, Pedro Henrique Ayres Brunetto and Rafael Ferreira Gregolin, Revista Brasileira de Ensino de Física 38, e1301 (2016).

[16] Calin Galeriu, Scott Edwards and Geoffrey Esper, The Physics Teacher 52, 157 (2014).

[17] SN Sen, Acoustics, Waves and Oscillations (New Age International Limited, New Deli, 1990).

[18] R Resnick, D Halliday and KS Krane, Fisica 2 (LTC, São Paulo, 2003).

[19] F Ramalho Júnior, NG Ferraro, and PAT Soares, Os Fundamentos da Física vol. 2 - Termologia, Óptica Geométrica e Ondas (Editora Moderna, São Paulo, 2007).

[20] F. Everest, The Master Handbook of Acoustics (McGrawHill, New York, 2001).

[21] PP Vaidyanathan, IEEE Transactions on Circuits and Systems I: Fundamental Theory and Applications 48, 1094 (2001).

[22] Mariana Martínez Rodríguez and Jazmín González Gómez, Medidor de distancia por ultrasonido (2016).

[23] Daniel Barrera Núñez, Diseño e implementación de un cuadracóptero con sistema de control automático de estabilidad y comunicación inalámbrica de datos utilizando plataformas de hardware y software libre (2012).

[24] Jacob Millman, Microelectronics: Digital and Analog Circuits and Systems (McGraw-Hill, New York, 1979).

[25] Maik Schmidt, Arduino (Pragmatic Bookshelf, Raleigh, 2011).

[26] Mauricio Delbracio, Two Problems of Digital Image Formation: Recovering the Camera Point Spread Function and Boosting Stochastic Renderers by Auto-Similarity Filtering. PhD Thesis, École normale supérieure de CachanENS Cachan, 2013.

[27] Rafael C Gonzalez and Richard E Woods, Digital Image Processing (Pearson Education, New York, 2009).

[28] JY Dongju Liu, in: 2009 Ninth International Conference on Hybrid Intelligent Systems (IEEE, New York, 2009), p. 344-349.

[29] Mathworks, disponível em http://www.mathworks. com/help/images/ref/deconvblind.html acessado em 22/6/2017.

[30] Heather B Gonzalez and Jeffrey J Kuenzi, Science, Technology, Engineering, and Mathematics (stem) Education: A Primer (Library of Congress, Washington, D.C., 2012). 